\title{
MIGRAINOUS INFARCTION AS A COMPLICATION OF SPORADIC HEMIPLEGIC MIGRAINE IN CHILDHOOD
}

\author{
Reinaldo Teixeira Ribeiro', Mariana Machado Pereira Pinto², Thaís Rodrigues Villa', \\ Luana Tesser Gamba ${ }^{3}$, Célia Harumi Tengan ${ }^{4}$, Deusvenir de Souza-Carvalho ${ }^{4}$
}

According to the second edition of the International Classification of Headache Disorders (ICHD-II)', migrainous infarction (MI) is a complication of migraine with aura. $\mathrm{Ml}$ is diagnosed when one or more aura symptoms last longer than 60 minutes, and neuroradiological studies demonstrate ischemic stroke that potentially explains the symptoms. Stroke should not be attributed to another disorder. The ICHD-II also defines sporadic hemiplegic migraine (SHM) as a subtype of migraine with aura associated with fully reversible motor weakness in association to the typical aura symptoms (visual, sensory or dysphasic aura). Unlike familial hemiplegic migraine (FHM), familial history of migraine with motor weakness in first- or second-degree relatives is absent. $\mathrm{Ml}$ in childhood is very rare and epidemiological studies are scarce ${ }^{2}$. Reports of incidence of migrainous stroke in this group range from $0.5 \%^{2}$ to $1.7 \%^{3}$. A fairly and diligent review of the literature found no previous reports of MI during childhood following SHM in Brazil.

Herein we report a case of Ml following SHM in a child. We obtained written informed consent to publish the case, as well as the results of genetic testing. The principles outlined in the declaration of Helsinki were followed.

\section{CASE}

A 10-year-old boy was initially referred to our service on May of 2004, with a 2-year history of attacks of bifrontal and throbbing headache, preceded by right hemi-hypoesthesia and hemiparesis that typically lasted less than 60 minutes. Headache attacks were of moderate intensity and were associated with photophobia and phonophobia. Frequency was around 3 per month and duration ranged from 10 to 72 hours.

Family reported a single episode of headache in which the associated right hemiparesis lasted about three days. Although attack was longer and clearly not suggestive of a benign migraine attack, it had not been investigated.

The patient had no relevant prior medical history. Relevant familial history included mother suffering from migraine with vi-

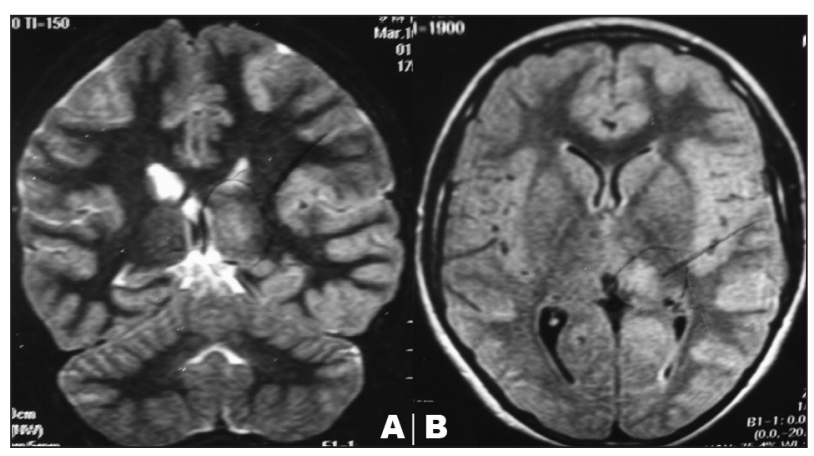

Fig 1. Coronal $T 2$ weighted $[A]$ and axial T2-weighted FLAIR [B] magnetic resonance imaging showing left thalamus (pulvinar) infarction.

sual aura, and brother with a past episode of transient left hemiparesis (without headache) in the context of varicella infection.

Two months before the first consultation, patient suffered a partial seizure, characterized by right hemi-body hypertonia, cephalic deviation and gaze shift to the right side, during a typical attack of hemiplegic migraine. Patient recovered totally and neurological exam was normal. Magnetic resonance imaging revealed a left thalamic (pulvinar) lesion, suggestive of ischemia (Fig 1). The patient was then referred to our division for investigation and treatment.

A comprehensive complementary investigation with blood tests, imaging tests, genetic tests, EEG and CSF for ischemic stroke was performed and revealed no abnormalities. Treatment with flunarizine yielded adequate control of the migraine attacks, but it was suspended due to significant drowsiness and weight gain. Patient responded well to propranolol and is free of headaches since then (headache free for 2 years).

\section{Mutation screening}

Screening for DNA mutations were conducted on peripheral blood. We performed sequencing of the coding regions and exon-intron boundaries of the genes previously associated with FHM (CACNA1A, ATP1A2, SCN1A) 4 , including the promoter regions for the first two. Analyses showed only one alteration in

\footnotetext{
INFARTO MIGRANOSO COMO UMA COMPLICAÇÃO DE MIGRÂNEA HEMIPLÉGICA ESPORÁDICA NA INFÂNCIA

Department of Neurology, Federal University of São Paulo, São Paulo SP, Brazil: ${ }^{1} \mathrm{MD} ;{ }^{2} \mathrm{MD}, \mathrm{M} . \mathrm{Sc} ;{ }^{3}$ Biologist; ${ }^{4} \mathrm{MD}$, PhD.

Received 4 February 2009, received in final form 30 June 2009. Accepted 8 July 2009.

Dr. Deusvenir de Souza-Carvalho - Rua Pedro de Toledo 980 / 33 -04039-002 São Paulo SP-Brasil. E-mail: deusveni@provida.org.br
} 


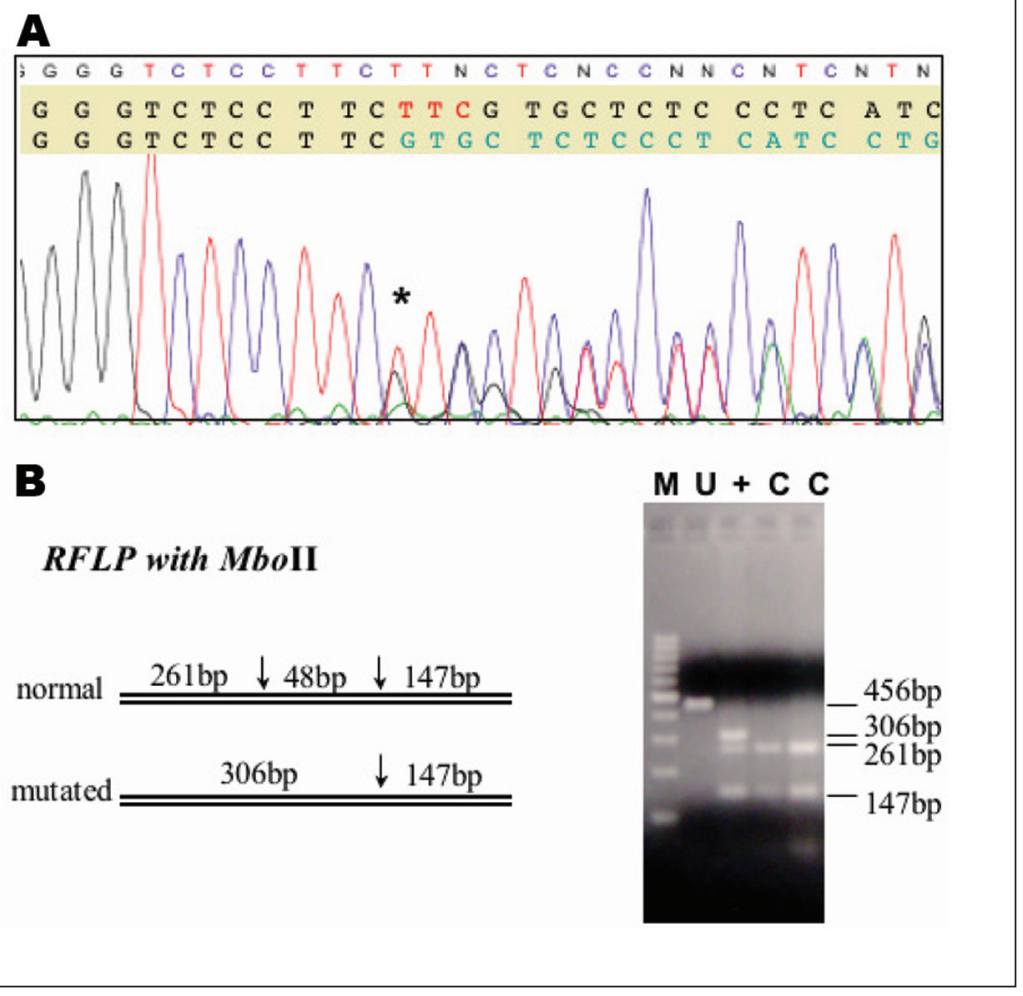

Fig 2. Sequencing analysis $[A]$ and RFLP study with Mboll [B]. In [A], the sequence became unreadable after a heterozygous modification ${ }^{*}$ ) caused by two superimposed sequences: the normal one (top) and the one with TTC deletion (bottom). In [B], the mutation leads to the loss of one Mboll restriction site (left) and an abnormal band (306bp) could be detected after agarose gel electrophoresis (right). M: molecular weight marker; U: uncut; +: patient; C: control. exon 8 of ATPIA2, a heterozygous deletion of 3 nucleotides (TTC) predicting F304del in the encoded protein (Fig 2A). The protein location of this abnormality is not conserved across different species. RFLP (restriction fragment length polymorphism) analysis showed that this abnormality was present neither in other family members (parents and brother) nor in 200 control chromosomes (Fig 2B). We also excluded the most common mutations associated with mitochondrial encephalomyopathy, lactic acidosis, and stroke-like episodes or MELAS (A3243G in mitochondrial DNA) and cerebral autosomal dominant arteriopathy with subcortical infarcts and leukoencephalopathy or CADASIL (exons 3 and 4 of $\mathrm{NOTCH} 3$ ).

\section{DISCUSSION}

The association of MI and SHM in childhood is poorly understood due to the rarity of both entities. Among cases of ischemic stroke in childhood, Ml accounted for $17.4 \%{ }^{5}$ of the cases in a single retrospective study conducted without a standardized protocol, hence susceptible to biases. MI has not been described in several adult cases of $\mathrm{FHM}^{6}$ and $\mathrm{SHM}^{7}$ with neurological deficits lasting for several days.

According to some authors, the ICHD-II criteria for MI are too restrictive for use in the pediatric population ${ }^{3,8}$, requiring a revision. It is well known that the clinical features of migraine vary as a function of age, and that children are more likely to have attacks of shorter duration and bilat- eral location. These and other differences between the pediatric and adult populations were not fully addressed by the ICHD-II criteria. Failure to fulfill the migraine with aura criteria is one of the possible reasons to explain the small number of $\mathrm{Ml}$ cases previously reported.

Ischemic stroke during childhood is an infrequent condition $^{5}$ with many potential risk factors. Accordingly, the diagnostic process should be directed towards identifying as many of risk factors as possible. The proportion of patients where no risk factors are identified has progressively decreased as a function of our better understanding of the etiology of Ml, which has been accompanied by improved investigation methods ${ }^{9}$. The extensive investigation necessary to exclude other causes of ischemic stroke is probably another reason for the lack of MI diagnosis in childhood.

Our patient fulfilled ICHD-II criteria for MI and for SHM. The complementary studies performed to exclude other causes of ischemic stroke were those suggested by the Royal College of Physicians ${ }^{9}$. After screening the three genes previously associated to FHM, we could only find a 3 nucleotide deletion in the ATP1A2 gene. This modification was not described before and predicts one aminoacid deletion (F304del) that does not lead to a truncated protein. Although it was not detected in controls, this region is not conserved among different species, which could suggest that it represents a polymorphism. There are few 
reports of mutations in FHM genes in SHM patients ${ }^{4,10}$. Phenotype-genotype correlations in these patients and family members demonstrated the presence of mutation carriers in migraine with aura (or in individuals without migraine $)^{4,10}$. Thus, the mutation is not sufficient to indicate pathogenicity. Further studies are needed to establish the role of this mutation in this phenotype.

Migraine complications should be promptly investigated to exclude other causes. Prophylaxis should be initiated as soon as possible to control migraine attacks that could lead to additional complications.

\section{REFERENCES}

1. Headache Classification Subcommittee of the International Headache Society. International Classification of Headache Disorders, second edition. Cephalalgia 2004;24(Suppl 1):S1-S160.

2 Barlow CF. Headaches and migraine in childhood. Clin Dev Med 1984; 91:138-154.

3. Rossi LN, Penzien JM, Deonna TH, Goutières F, Vassella F. Does mi- graine-related stroke occur in childhood? Dev Med Child Neurol 1990; 32:1005-1021.

4. de Vries B, Freilinger T, Vanmolkot KRJ, et al. Systematic analysis of three FHM genes in 39 sporadic patients with hemiplegic migraine. Neurology 2007;69:2170-2176.

5. Benito-León J, Guerrero AL, Simón R, Mateos F. Ictus isquémico en la edad pediátrica. Rev Neurol 1998;27:631-634.

6. Dodick D, Roarke M. Familial hemiplegic migraine: permanent attackrelated neurologic deficits. Headache 2007;47:1210-1223.

7. Jacob A, Mahavish K, Bowden A, Smith ETS, Enevoldson P, White RP. Imaging abnormalities in sporadic hemiplegic migraine on conventional MRI, diffusion and perfusion MRI and MRS. Cephalalgia 2006; 26:1004-1009.

8. Ebinger F, Boor R, Gawehn J, Reitter B. Ischemic stroke and migraine in childhood: coincidence or causal relationship? J Child Neurol 1999; 14:451-455

9. Paediatric Stroke Working Group. Stroke in childhood: clinical guidelines for diagnosis, management and rehabilitation. London: Royal College of Physicians, 2004:23-24.

10. Thomsen LL, Oestergaard E, Bjornsson A, et al. Screen for CACNA1A and ATP1A2 mutations in sporadic hemiplegic migraine patients. Cephalalgia 2008;28:914-921. 